Research Article

\title{
Agronomic Practices, Genetic Diversity and Population Structure of Moringa oleifera (Lam.) in Nigeria
}

\author{
Jacob Popoola ${ }^{1,2}$, David Igwe ${ }^{3,4}$, Opeyemi Jegede ${ }^{5}$, Victoria Iwu ${ }^{6}$, Adegoke Adegbite ${ }^{7}$ and \\ Conrad Omonhinmin ${ }^{1}{ }^{2}$. \\ 1Department of Biological Sciences, College of Science and Technology, Covenant University, P.M.B. 1023, \\ Canaanland Ota, Ogun State, Nigeria; jacob.popoola@covenantuniversity.edu.ng; \\ conrad.omonhinmin@covenantuniversity.edu.ng \\ 2Biotechnology Cluster Group, CUCRID Building, Covenant University, Ota, Ogun State, Nigeria. \\ 3Department of Biotechnology, Ebonyi State University, P.M.B 053, Abakaliki, Ebonyi State, Nigeria; \\ dave25dato@yahoo.com. \\ 4Department of Natural Sciences, Bowie State University, 14000 Jericho Park Road, Bowie, Maryland, 20715 \\ USA. \\ 5Sustainable Forestry Management Department, Seed Section, Forestry Research Institute of Nigeria, P.M.B. \\ 5054, Jericho, Ibadan, Oyo State; opeyemijege20.j0@gmail.com \\ 6Bioscience, International Institute of Tropical Agriculture, IITA, Ibadan, Nigeria: v.iwu@cgiar.org \\ 7Department of Biological Sciences, Ondo State University of Science and Technology, Okitipupa, Ondo \\ State, Nigeria; gokeadegbite@yahoo.co.uk
}

*jacob.popoola@covenantuniversity.edu.ng; Tel.: (+234 806464 0018).

Abstract: Evaluation of agronomic practices, genetic diversity and population structure of Moringa oleifera (Lam.) is crucial to its sustainable utilization to ensure food and nutritional security. Four agronomic practices of field preparation and soil analysis, regeneration, weeding and pruning, as well as harvesting, were adopted. Genetic diversity and population structure of 20 populations were evaluated using amplified fragment length polymorphism (AFLP) primer pairs (E-ACC/M$\mathrm{CAC}$ and $\mathrm{E}-\mathrm{ACA} / \mathrm{M}-\mathrm{CAG}$ ). The effects of agronomic practices on leaf quantity production were evaluated using standard procedures. The physico-chemical and morphological data were analyzed using descriptive statistics, while genetic diversity, population structure, dendrogram reconstruction, and Principal Component Analysis (PCA) were analyzed from the AFLP genetic data. Significant effects $(\mathrm{P} \leq 0.05)$ of agronomic practices on the quantity of leaf production were recorded across the accessions. The two primer pairs generated a total of 80 alleles with a mean major allele frequency of 0.0250. Gene diversity and polymorphic information content (PIC) values were high with a mean of 0.98 and 0.974 , respectively. The mean values of effective number of alleles $(\mathrm{Ne}), \mathrm{Nei}$ 's genetic diversity $(\mathrm{H})$, and Shannon's information index $(\mathrm{I})$ values from the accessions were 1.2952 \pm 0.0195 , $0.2277 \pm 0.0118$, and $0.3882 \pm 0.0153$. The Gst value of 0.0490 indicated that $5 \%$ of the total genetic divergence was among the population while $95 \%$ within the population. Dendrogram reconstruction with genetic distance ranging from 0.87 to 0.96 segregated the accessions into eleven clusters while PCA generated six cluster groups. Field preparation and physico-chemical soil properties, regeneration, weeding and pruning, and stand development, as well as harvesting, influenced the leaf yield and genetic diversity observed in this study. The genetic data revealed that some accessions were clustered along eco-geographical lines while others grouped disparately. Identified potential parent genotypes with valuable and desirable genetic traits can be exploited for commercial, breeding and conservation purposes to ensure sustainable utilization of the species in Nigeria.

Keywords: Agronomic practices; agrobiodiversity; AFLP; climate change; cluster analysis; genetic diversity; Moringa oleifera; food and nutrition security 


\section{Introduction}

In Africa, the population is rapidly growing and expected to double by the year 2050 whereas, food and nutritional security attainment are not guaranteed. Nigeria with a current population estimated to be above 180 million people would be around 400 million by then. Nigeria has great potentials for food production to ensure food and nutritional security, yet it is one of the foods and nutrition-deficient nations in Africa. Its agrobiodiversity including land, water and plants as well as animals are constantly under pressure resulting in the degradation of genetic resources. The combined effects of climate change, terrorism and increased pressure on land are negatively impacting sustainable agriculture for food and nutritional security, as well as human well-being. Presently, many agricultural fields and farms are being constantly destroyed for various reasons leading to untoward suffering in many parts of Nigeria and other African countries. Internal displacement of people is on the increase which requires global attention and efforts to mitigate these crisis. More so, traditional agronomic practices of many indigenous species are being neglected resulting in low yield and neglect of many important species thereby limiting food production. Low crop yields and associated repercussions are also affecting global food supply and food security. The promotion of indigenous biodiversity and incorporation of nutrition into food value chains will ensure sustainable and resilient food systems, improve diet quality and increase smallholder farmers' incomes. Diversification of diets and utilization of other important species other than the commonly utilized ones have been identified as a panacea to food and nutritional insecurity to achieve the United Nation Sustainable Development Goals of zero hunger, no poverty, and good health [1,2].

Drumstick, Moringa oleifera (Lam.) of the Moringaceae family is one of the important multipurpose foods and medicinal plants that has the potential to contribute to food and nutritional security, health care and the environment as well as the socio-economic livelihood of Sub-Sahara Africa people [3]. It is usually cultivated as a food plant, leafy vegetable and as an herbal source containing several pharmacological properties [4-6]. Remarkably, Moringa tree can survive in diverse ecological settings, withstand abiotic and biotic stresses including high temperatures, heat, and drought as well as insect pest attacks, thus capable of mitigating the effects of climate change $[7,8]$. Ensuring sustainable food and nutritional security will require several strategies including consistent cultivation, conservation and genetic characterization of many unrecognized and under-exploited species alongside the reformation of traditional agronomic practices. Also, in the quest for sustainable development, safer environment, and good healthcare services, bio-fortification and dietary diversification strategies should be strengthened to further enrich and enhance the nutritional and medicinal contents of food and plant species. In Nigeria, the increased demand for natural food and nutrition has led to increased cultivation and utilization of Moringa oleifera and its parts together with Moringa based-products even though silvicultural/agronomic management practices have not been clearly established to make adequate provision for continuous supply toward sustainable utilization $[3,8]$.

The effects of agronomic practices on leaf quantity production as well as other parts are crucial to functional food and nutritional security. The genetic resources of M. oleifera have not been adequately tapped and harnessed for utilization, conservation, breeding and improvement purposes. Presently, the available germplasm are mainly landraces that are narrowly represented in ex situ collections while in situ collections are poorly managed and conserved [8]. Genetic characterizations of plant species germplasm and the relationships between or among eco-geographic variants may provide genetic insights toward sustainable utilization, breeding, and conservation of their genetic resources $[9,10]$. In addition, successful crop improvement strategies are largely dependent on genetic characterization/evaluation to identify potential parents for hybridization and heterosis crossing [11]. Morphological and molecular markers are usually engaged in the evaluation of genetic diversity to achieve varied needs. Recently, studies on phenotypic intraspecific variability of M. oleifera from Nigeria revealed a considerable level of diversity among the accessions of ecotypes, and/or landraces valuable for conservation, genetic improvement and utilization purposes [3,12]. Such studies, however, are hampered by the long period required for progenies to mature, lack of consistency between phenotypic traits and outcrossing [13]. So far, DNA markers such as random amplified 
polymorphic DNA (RAPD) and simple sequence repeats (SSR) have been employed in the study of genetic diversity, genetic relationships and geographic origin among the landraces of Moringa oleifera from Nigeria $[8,12,14]$. Several studies have also shown that RAPD, amplified fragment length polymorphism (AFLP) and SSR are very efficient in the assessment of genetic variation, population structure and spread pattern in tree species including M. oleifera [15-19]. AFLP, in particular, is highly effective to explore variation throughout the entire genome both in coding and non-coding DNA regions without any prior sequence information [20]. AFLP is highly reproducible, generates multilocus polymorphisms in single assay and thus efficient in germplasm diversity evaluation [20,21]. Although Muluvi et al [15] had previously provided genetic variation data among 140 genotypes of Moringa oleifera from seven different populations of 20 trees per population from South India, Southern Malawi and Kenya using AFLP, such studies have not been extended to Nigerian populations. AFLP markers have not been used to decipher genetic diversity, distance, and ecogeographic alignment as well as the population structure of the species from Nigeria. Genetic diversity in natural plant populations is sustained by heterogeneity in relation to environmental variation/changes, distance, and adaptation [22,23].

For the first time in Nigeria, this study presents agronomic/silviculture practices, assessment of genetic diversity and population structure, as well as eco-geographical alignment of 40 landraces of Moringa oleifera, collected from 20 states of different ecological zones in Nigeria. The specific objectives of the present study include:

i. Investigate the effects of silvicultural/agronomic management practices on leaf production ability of Moringa oleifera to meet the increasing demand as a leafy vegetable and for Moringabased products,

ii. Evaluate and compare the genetic diversity and population structure of 40 accessions of Moringa oleifera from different agro-ecological zones in Nigeria using AFLP marker targeted toward breeding and sustainable utilization, and,

iii. $\quad$ Assess spread pattern among the Moringa oleifera accessions using AFLP markers

\section{Materials and Methods}

\section{Agronomic /Silviculture management practices}

Moringa oleifera pods were harvested from five accessions in three locations (Osiele in Ogun state, Akure in Ondo state and Ibadan in Oyo state) within Southwest Nigeria (Figure 1). Field preparation and soil analysis, planting and spacing method, weed controlling management and pruning as well as harvesting modes were adopted as silvicultural /agronomic management practices.

\section{Field preparation and Soil Analysis}

Nursery experiments and field assessment study were conducted at the nursery and arboretum, Department of Sustainable Forest Management, Forestry Research Institute of Nigeria, Ibadan, Oyo State. The field site was well prepared, slashed and cleared while plant litters and debris were packed and discarded. The physico-chemical properties of the soil were analyzed following standard procedures of soil analysis [24].

\section{Planting and Spacing Methods}

A total of fifty seeds (50) of ten seeds each from the five accessions were randomly selected and planted in germination boxes filled with sterilized river sand. Two weeks after planting, forty (40) uniformly growing seedlings (eight seedlings per accession) were transplanted into a planting poly pot $(24 \mathrm{~cm} \times 18 \mathrm{~cm})$ containing topsoil. The pots were properly labeled as A, B, C, D, and E. The seedlings were arranged in the nursery shed for two weeks to stabilize and watering was done once daily. Eight seedlings per accession were transplanted to the field (one potted seedling in a hole) at the onset of the rainy season at a standard spacing of $1 \mathrm{~m} \mathrm{X} 0.75 \mathrm{~m}$ for small trees. 
Weed controlling management, Prunning and harvesting

Regular field weeds were observed and hand weeding was thoroughly carried out four weeks after transplanting and continuously maintained regularly until the end of the experiment. At four months old, two plants from each accession were pruned with a pair of secateurs at heights of $20 \mathrm{~cm}$, $40 \mathrm{~cm}$ and $60 \mathrm{~cm}$ from plant base at soil level and two plants were left to serve as control for each of accession (no pruning all). At four weeks intervals for a period of 24 weeks, all leaves including the leaf stalk were harvested while fresh weight $(\mathrm{g})$ of the harvested leaves per treatment was determined.

Data analysis

The experiment was arranged in a $3 \times 5 \times 3$ factorial experiment in a complete randomized design. Factor A was the location, Factor $B$ was the accession while Factor $C$ was the pruning level. Leaves per accession were bulked, data were collected and analyzed using descriptive statistics while results were presented in charts and tables.

Genetic Diversity, Population structure and Spread pattern using AFLP

Plant samples and collection areas

A total of 40 accessions of Moringa oleifera previously characterized based on agro-morphological traits were selected and analyzed for genetic diversity, population structure and spread pattern [3]. Source of samples, collection mode, and the number of accessions collected have been earlier reported $[3,25]$. One of the samples was identified by the first author and authenticated at the Forest Research Institute of Nigeria (FRIN), Ibadan, Oyo State, Nigeria and allocated with a forestry herbarium number (FHI No: 110313). The herbarium sample was also assigned a voucher number (Mo/Bio/H816) and deposited in the depository of the Department of Biological Sciences, Covenant University, Ota, Ogun State, Nigeria. The accessions and collection areas spread across the Northern and Southern parts of Nigeria as shown in Figure 1. 


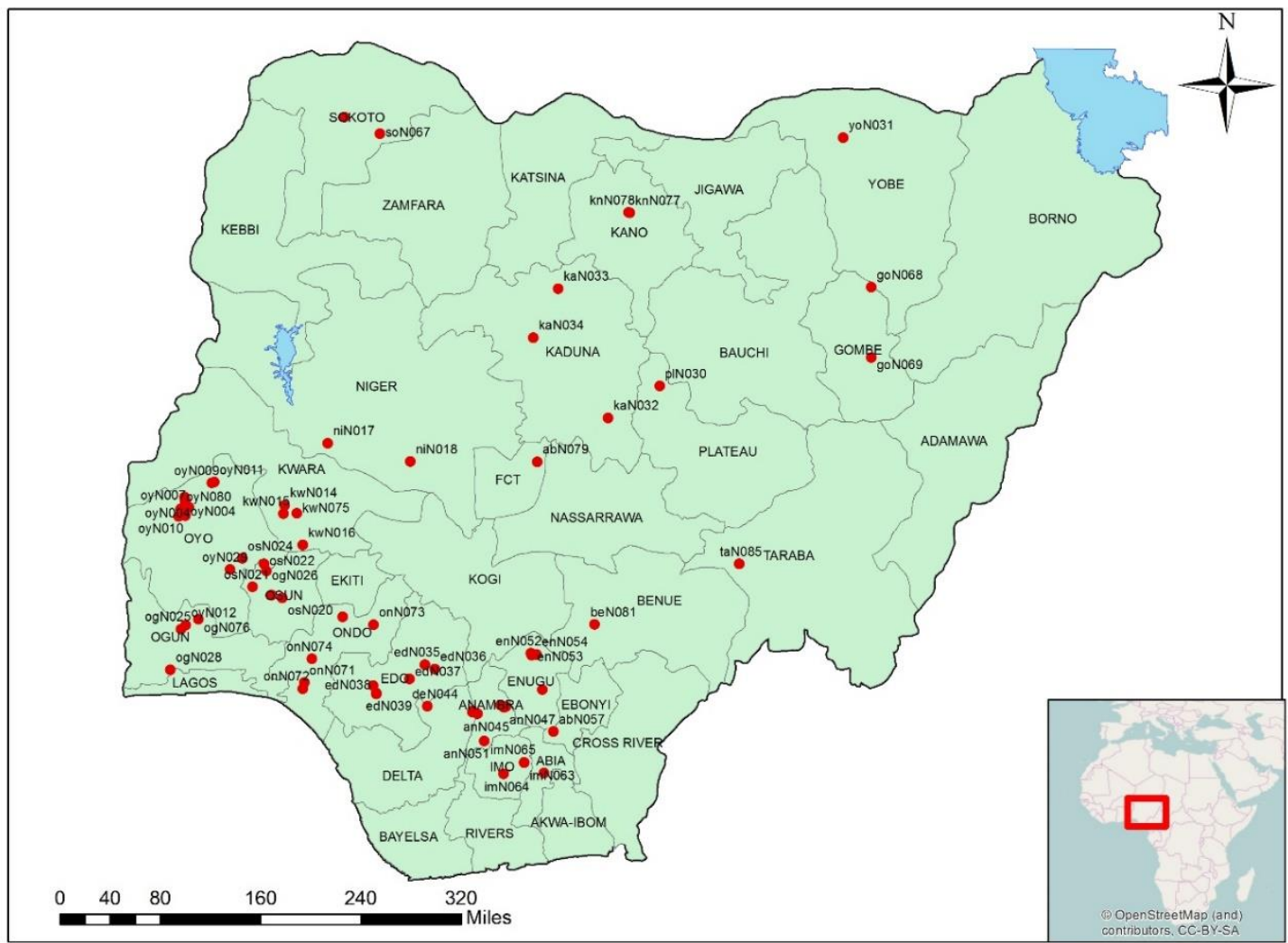

Figure 1. Areas of collection of the 40 accessions of Moringa oleifera used for this study. 


\section{DNA Extraction}

Young leaves from 4-weeks-old seedlings were collected in sample bags properly labeled for each accession. The leaf samples were lyophilized for 48 hours and kept at $-20^{\circ} \mathrm{C}$. Genomic DNA was extracted using the modified SDS method [26]. A supplementary step was introduced to the extraction protocol to eliminate secondary metabolites and phenolic compounds with the addition of $3 \%$ Polyvinylpyrrolidone (PVP) to the genomic DNA. NanoDrop spectrophotometer (ND-1000) and $1 \%$ agarose gel were used to determine the quality and quantity of the extracted DNA prior to amplification.

\section{Amplified Fragment Length Polymorphism (AFLP) protocol}

Six primer pairs were initially screened on 10 accessions of $M$. oleifera and based on clear banding patterns, good fragments and polymorphism, two primer pairs (M-CAC/E-ACC and M-CAG/E-ACA) were selected and used for this study. The AFLP analysis was performed using AFLP Analysis System I and AFLP starter primer kit (catalog number 10544-013 and 10483-014) from Invitrogen Life Technologies. The kit instruction manual was followed for: genomic DNA Restriction Endonuclease Digestion; Ligation of Adaptors to the digested DNA and amplification reactions consisting of a preamplification and selective amplification, respectively. The above processes were all performed in a thermocycler GeneAmp PCR System 9700 (Applied Biosystems). Amplified fragments from primer pairs showing high polymorphisms were separated on $6 \%$ denaturing polyacrylamide gel for 2 hours and visualized using the AFLP silver-staining kit.

\section{Data analysis}

DNA fragment analysis software GelQuest version 3.5.3.0 [27] was used to score fragments of $100-1000$ bp with a peak height of 1000 reflective fluorescent units (RFUs). The Gel output files were converted into FAS files and subsequently generated the binary character matrix. The FAS files of the binary character matrix were converted into excel format (Supplementary List 1) and subjected to various analyses. PowerMarker software program [28] was used to determine genetic diversity parameters such as the number of alleles (Ne), gene diversity (GD), major allele frequency (MAF), Nei's genetic diversity $(\mathrm{H})$ and Shannon's information index (I) [29]. The Polymorphic Information Content (PIC) per primer pair was generated while percentage polymorphisms were estimated according to Popoola et al. [30]. Population structure including total gene diversity (Ht), gene diversity within a population (Hs), coefficient of gene differentiation (Gst) as well as an estimate of gene flow was evaluated using Popgene software version 3.5 [31]. NTYSYSpc 2.1 software [32] was engaged to generate the pairwise distance matrices based on Jaccard's similarity coefficient [33] and generated a dendrogram based on the unweighted pair-group method with arithmetic average (UPGMA). A scattered plot of the Principal Component Analysis (PCA) of the 40 accessions of $M$. oleifera was also generated from the AFLP data.

\section{Results}

\subsection{Agronomic/Silviculture practices: Physico-chemical properties of soil, regeneration, and weeding.}

Table 1 presents data on the physico-chemical properties of the soil with nutrient values of soil parameters. The soil has a $\mathrm{pH}$ value of 5.72, organic carbon (\%) 1.62, organic matter (\%) 2.79 while total nitrogen $(\%)$ was 0.14 . Other soil parameters including potassium, calcium, sodium, manganese and magnesium all in $\mathrm{Cmol} / \mathrm{kg}$ were recorded in Table 1 . All transplanted potted seedlings survived and maintained a continuous increment at the adopted spacing for the first 4 months of establishment. Routine weeding of the rapid flush of Pennisetum purpurium (the most prominent weed) prevented nutrient loss from the soil and enhanced healthy seedling growth. 
3.1.1. Pruning, decapitation at different levels and harvesting: Effects on leaf quantity production

The quantity of Moringa oleifera leaves produced over a period of six (6) months at a control level is presented in Figure $2 \mathrm{~A}$ while decapitation at different levels of $20 \mathrm{~cm}, 40 \mathrm{~cm}$ and $60 \mathrm{~cm}$, respectively are shown in Figure $2 \mathrm{~B}-\mathrm{D}$. The charts revealed that leaf quantity decreased but varied with time across locations from the first month to the fourth month and later increased for the remaining two months in the control. Moringa oleifera seedlings from Akure recorded a higher leaf quantity of $6.43 \mathrm{~g}$, followed by Oyo with $6.12 \mathrm{~g}$ and the least was Abeokuta seedlings with $5.31 \mathrm{~g}$. The results in Figure 2B showed the decapitation level at $20 \mathrm{~cm}$ and the quantity of leaf with a moderately steady increment across the locations for the first two months. Akure and Oyo locations experienced a drastic decrease in leaf production during the third month. In the fourth month, leaf quantity production maintained a gradual increment across the locations until the end of the experiment in the $6^{\text {th }}$ month. Figure $2 \mathrm{C}$ and 2D, show leaf quantity production at $40 \mathrm{~cm}$ and $60 \mathrm{~cm}$ decapitation levels, respectively with varying levels of leaf production.

The results showed that at the $40 \mathrm{~cm}$ decapitation level, Oyo location maintained the highest leaf quantity production, followed by Akure with a low leaf quantity level reducing per time for the first 4 months and increased for the last two months. However, Abeokuta had the least leaf quantity over time and showed a gradual increment after the $5^{\text {th }}$ month. Significant effects at $(P \leq 0.05)$ of agronomic practices on leaf quantity production were recorded across the accessions.

Table 1. Physico-chemical properties of the soil of the site used for field trials to determine leaf production of decapitated Moringa oleifera seedlings.

\begin{tabular}{cc}
\hline Soil parameters & Values \\
\hline pH & 5.72 \\
Organic Carbon (\%) & 1.62 \\
Organic Matter $(\%)$ & 2.79 \\
Total Nitrogen $(\%)$ & 0.14 \\
Potassium (Cmol/kg) & 0.03 \\
Sodium (Cmol $/ \mathrm{kg})$ & 0.46 \\
Calcium $(\mathrm{Cmol} / \mathrm{kg})$ & 2.74 \\
Magnisiumg $(\mathrm{Cmol} / \mathrm{kg})$ & 1.40 \\
Manganese $(\mathrm{Cmol} / \mathrm{kg})$ & 26.50 \\
Copper $(\mathrm{mg} / \mathrm{kg})$ & 4.20 \\
Zinc $(\mathrm{mg} / \mathrm{kg})$ & 12.3 \\
Iron $(\mathrm{mg} / \mathrm{kg})$ & 64.00 \\
Potassiun $(\mathrm{Mg} / \mathrm{kg})$ & 1.05 \\
Sand $(\%)$ & 80.50 \\
Silt $(\%)$ & 5.00 \\
Clay $(\%)$ & 14.50 \\
\hline
\end{tabular}



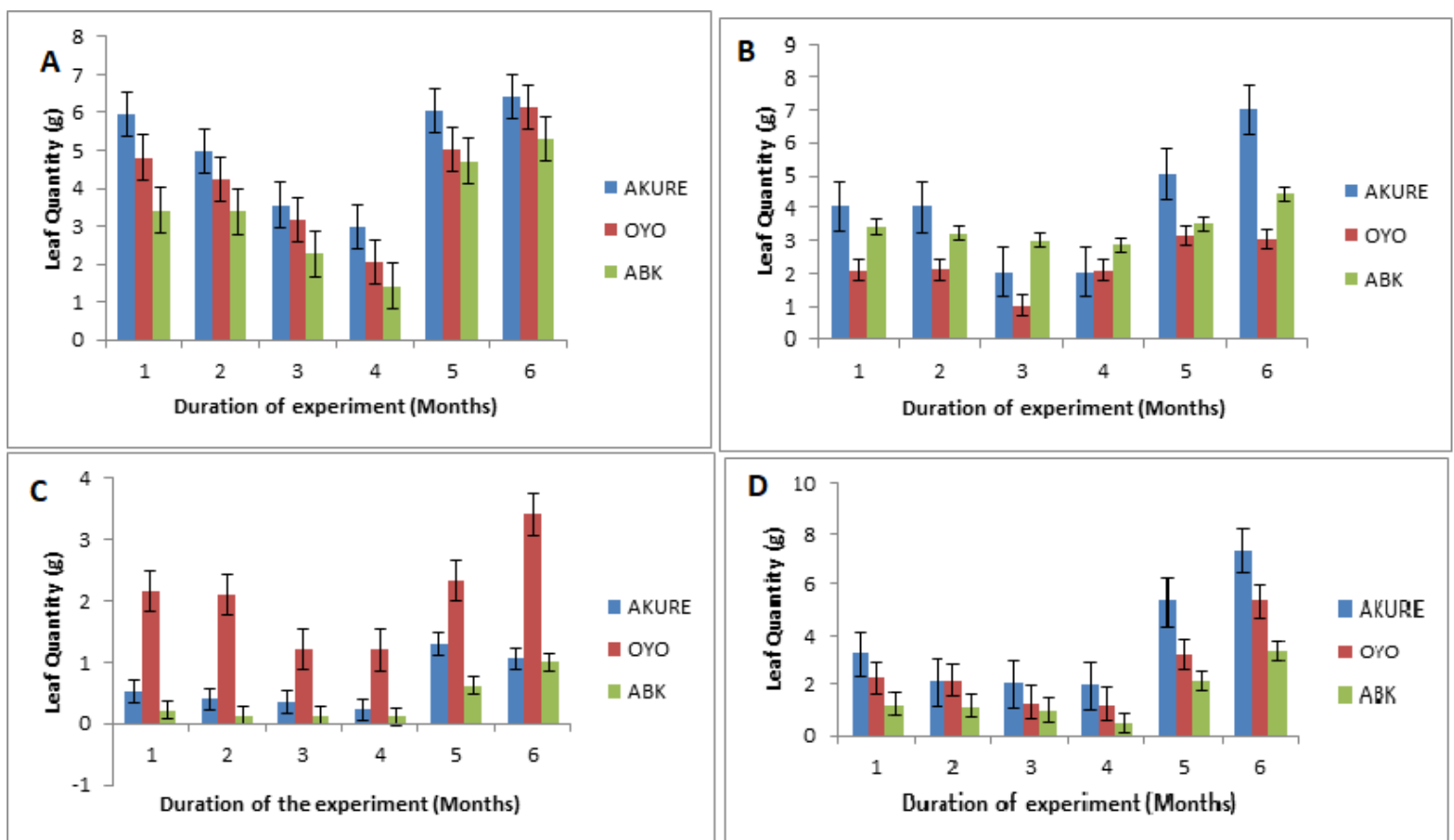

Figure 2: Effects of agronomic/silviculture practices on leaf quantity production of Moringa oleifera seedlings selected from three locations (Akure, Oyo, and Abeokuta (ABK))

A: Control level of decapitation for leaf quantity production of Moringa oleifera seedlings

B: $20 \mathrm{~cm}$ decapitation level for leaf quantity production of Moringa oleifera seedlings

C: $40 \mathrm{~cm}$ decapitation level for leaf quantity production of Moringa oleifera seedlings

D: $60 \mathrm{~cm}$ decapitation level for leaf quantity production of Moringa oleifera seedlings 
Sequences and genetic diversity estimates

The sequences of the selective primer combinations and adaptors are shown in Table 2. The data in Table 3 showed a summary of the descriptive statistics of the genetic diversity parameters evaluated for this study. A significant variation in band intensity, amplified product size, and overall banding pattern were observed among the accessions. The two primer pairs generated a total of 80 alleles with a mean major allele frequency of 0.0250 . Monomorphic bands were few and less than $10 \%$ of the total bands recorded. The fragment size scored across the 40 accessions of $M$. oleifera studied ranged from 100 to 1000 base pairs (bp). Primer E-ACC/M-CAC generated 859 bands and $854(99.4 \%)$ were polymorphic while primer E-ACA/M-CAG generated 413 bands out of which (96\%) were polymorphic (Table 3). A total number of 80 alleles were recorded with a mean major allele frequency of 0.0250 . Gene diversity and PIC values were high with 0.974 and 0.974 , respectively, indicating high discriminatory power of the AFLP markers and thus higher genetic differentiation within populations. 
Table 2: Amplified fragment length polymorphism adapters and sequences for $M$. oleifera amplification

\begin{tabular}{cc}
\hline Adapters/Primers & Sequences \\
\hline EcoRI & 5'-CTCGTAGACTGCGTACC-3' \\
MseI & 3'-CATCTGACGCAATGGTTAA-5' \\
& 5'-GACGATGAGTCCTCAG-3' \\
MseI Primer & 5'-GATGAGTCCTGAGTAAC-3' \\
M-CAC & \\
M-CAG & 5'-GACTGCGTACCAATTCACC-3' \\
EcoRI Primer & 5'-GATGAGTCCTGAGTAACAG \\
E-ACC & \\
E-ACA & 5'-GACTGCGTACCAATTCAAC-3' \\
& 5'-GATGAGTCCTGAGTAACAG-3' \\
\hline
\end{tabular}

Table 3: Number of percentage polymorphisms, gene diversity and polymorphic information content per primer combination.

\begin{tabular}{lllllllll}
\hline Marker & NB & NMB & NPB & PP\% & AN & MAF & GD & PIC \\
\hline E-ACA/M-CAG & 413 & 15 & 398 & 96 & 40 & 0.025 & 0.98 & 0.974 \\
E-ACC/M-CAC & 859 & 5 & 854 & 99.4 & 40 & 0.025 & 0.98 & 0.974 \\
Total & 1272 & 20 & 1252 & 195.4 & 80 & 0.050 & 1.96 & 1.948 \\
Mean & 636 & 10 & 626 & 97.7 & 40 & 0.0250 & 0.98 & 0.974 \\
\hline
\end{tabular}

NB -Bands counted, NMB -monomorphic bands, NPB -Polymorphic bands number, PP -Polymorphism percentage (\%), AN - Allele Number, MAF - Major Allele Frequency, GD - Gene Diversity, PIC - Polymorphic Information Content.

\section{Genetic diversity of Moringa oleifera as revealed by AFLP marker}

The genetic diversity in edN037 from Pax Benedicta Monastry in Edo State was identified to be highest with effective number of alleles $(\mathrm{Ne})$, Nei's genetic diversity $(\mathrm{H})$, and Shannon's information index (I) values of 1.3274, 0.2467 and 0.4123 , respectively (Table 4). On the other hand, the genetic diversity in the accession of beN081, collected from Otukpo in Benue State, was found to be the lowest, with $\mathrm{Ne}, \mathrm{H}$, and I values of $1.2295,0.1866$ and 0.3341 , respectively. The genetic diversity values of the Moringa oleifera accessions were ranked in an increasing order as beN081< edN035 < (onN072, oyN072, oyN010) < enN053 < (enN055, ogN076, ogN026, oyN005) < (anN049, onN070, osN024) < edN040 < (kwN015, niN018, oyN001) < (anN046, goN068, knN077, knN078, osn019, oyN004) < (imN064, ogN028, oyN009, plN030) < (anN051, taN085, yoN031 $)<($ kaN033, oyN003 $)<$ edN037. The overall mean values of $\mathrm{Ne}, \mathrm{H}$ and I obtained from the accessions collected within the twenty States of Nigeria were $1.2952 \pm 0.0195,0.2277 \pm 0.0118$, and $0.3882 \pm 0.0153$. 
Table 4: Genetic diversity of Moringa oleifera as revealed by amplified fragment length polymorphic markers

\begin{tabular}{|c|c|c|c|c|c|}
\hline Acc No & Area of Collection & State & $\mathrm{Ne}$ & $\mathrm{H}$ & $\mathrm{I}$ \\
\hline abN057 & Okpanku & Abia & 1.3144 & 0.2392 & 0.4029 \\
\hline abN059 & Umudike & Abia & 1.3101 & 0.2367 & 0.3998 \\
\hline anN049 & Enu Ifite & Anambra & 1.2843 & 0.2213 & 0.3801 \\
\hline anN051 & Ihiala & Anambra & 1.3058 & 0.2342 & 0.3966 \\
\hline anN046 & Unzik & Anambra & 1.2971 & 0.2291 & 0.3901 \\
\hline beN081 & Otukpo & Benue & 1.2295 & 0.1866 & 0.3341 \\
\hline deN041 & Asaba & Delta & 1.3187 & 0.2417 & 0.4061 \\
\hline edN035 & Ehanlen-Ewu & Edo & 1.2546 & 0.2029 & 0.356 \\
\hline edN040 & Ugbokwi & Edo & 1.2886 & 0.2239 & 0.3835 \\
\hline edN037 & Pax Benedicta Monastry & Edo & 1.3274 & 0.2467 & 0.4123 \\
\hline enN055 & Ugwuomu & Enugu & 1.2800 & 0.2188 & 0.3768 \\
\hline enN053 & Orba1 & Enugu & 1.2757 & 0.2161 & 0.3734 \\
\hline goN068 & Nafada & Gombe & 1.2971 & 0.2291 & 0.3901 \\
\hline imN064 & Ahiazu Mbaise & Imo & 1.3014 & 0.2316 & 0.3933 \\
\hline kaN033 & Tudun Wada & Kaduna & 1.3231 & 0.2442 & 0.4092 \\
\hline knN078 & Kofar kudu & Kano & 1.2971 & 0.2291 & 0.3901 \\
\hline knN077 & Army Barracks & Kano & 1.2971 & 0.2291 & 0.3901 \\
\hline kwN016 & Igosun & Kwara & 1.3101 & 0.2367 & 0.3998 \\
\hline kwN015 & Sobi & Kwara & 1.2928 & 0.2265 & 0.3868 \\
\hline niN018 & Bida & Niger & 1.2928 & 0.2265 & 0.3868 \\
\hline ogN025 & Abeokuta & Ogun & 1.3144 & 0.2392 & 0.4029 \\
\hline ogN028 & Covenant Univ & Ogun & 1.3014 & 0.2316 & 0.3933 \\
\hline ogN076 & Kila & Ogun & 1.2800 & 0.2188 & 0.3768 \\
\hline ogN026 & Olodo & Ogun & 1.2800 & 0.2188 & 0.3768 \\
\hline onN070 & Owena road & Ondo & 1.2843 & 0.2213 & 0.3801 \\
\hline onN074 & Ondo - Ore road & Ondo & 1.2971 & 0.2291 & 0.3901 \\
\hline onN072 & OSUSTECH & Ondo & 1.2672 & 0.2109 & 0.3665 \\
\hline osN019 & Ipetumodu & Osun & 1.2971 & 0.2291 & 0.3901 \\
\hline osN020 & OAU & Osun & 1.3187 & 0.2417 & 0.4061 \\
\hline osN024 & Owode & Osun & 1.2843 & 0.2213 & 0.3801 \\
\hline oyN003 & Aroje & Oyo & 1.3231 & 0.2442 & 0.4092 \\
\hline oyN001 & Oke-oro Saki & Oyо & 1.2928 & 0.2265 & 0.3868 \\
\hline oyN005 & Aba Oremeta Irawo & Oyo & 1.2800 & 0.2188 & 0.3768 \\
\hline oyN004 & Sango, Ago Are & Oyo & 1.2971 & 0.2291 & 0.3901 \\
\hline oyN009 & Alariwo Village & Oyo & 1.3014 & 0.2316 & 0.3933 \\
\hline oyN010 & Okaka & Oyo & 1.2672 & 0.2109 & 0.3665 \\
\hline plN030 & UniJos & Plateau & 1.3014 & 0.2316 & 0.3933 \\
\hline soN066 & Along Sokoto road & Sokoto & 1.3101 & 0.2367 & 0.3998 \\
\hline taN085 & Wukari (Fed. Univ) & Taraba & 1.3058 & 0.2342 & 0.3966 \\
\hline yoN031 & Bukarti/Karasuwa & Yobe & 1.3058 & 0.2342 & 0.3966 \\
\hline Overall mean & & & 1.2952 & 0.2277 & 0.3882 \\
\hline St. Dev & & & 0.0195 & 0.0118 & 0.0153 \\
\hline
\end{tabular}

$\mathrm{Ne}=$ Effective no of alleles, $\mathrm{H}=$ Nei's genetic diversity, and $\mathrm{I}=$ Shannon's information Index. 
Population structure of Moringa oleifera as revealed by AFLP markers

The genetic variation within the Moringa oleifera accessions from twenty (20) States revealed that accession edN037 collected from Pax Benedicta Monastry in Edo State of Nigeria, had highest values of total gene diversity $(\mathrm{Ht})$, gene diversity within population $(\mathrm{Hs})$, coefficient of gene differentiation (Gst) and level of gene flow (Nm) of 0.2467, 0.2375, 0.0372 and 12.9513, respectively (Table 5). Contrarily, the beN081 accession obtained from Otukpo in Benue state had the lowest values of $\mathrm{Ht}$, Hs, Gst, and Nm as 0.1866, 0.1649, 0.1163 and 3.8000, respectively. The overall values of Ht, Hs, Gst, and $\mathrm{Nm}$ obtained from the entire populations were $0.2277,0.2166,0.0490$ and 9.7066, respectively. The Gst value recorded 0.0490 indicating about $5 \%$ of the total genetic divergence among the populations and the remaining $95 \%$ within the populations. 
Table 5: Population structure of Moringa oleifera as revealed by amplified fragment length polymorphism markers

\begin{tabular}{|c|c|c|c|c|c|c|}
\hline Acc No & Area of Collection & State & $\mathrm{Ht}$ & Hs & Gst & $\mathrm{Nm}$ \\
\hline abN057 & Okpanku & Abia & 0.2392 & 0.2275 & 0.0488 & 9.7479 \\
\hline abN059 & Umudike & Abia & 0.2367 & 0.2293 & 0.0312 & 15.5257 \\
\hline anN049 & Enu Ifite & Anambra & 0.2213 & 0.214 & 0.0334 & 14.4873 \\
\hline anN051 & Ihiala & Anambra & 0.2342 & 0.2214 & 0.0545 & 8.6786 \\
\hline anN046 & Unzik & Anambra & 0.2291 & 0.2174 & 0.0509 & 9.314 \\
\hline beN081 & Otukpo & Benue & 0.1866 & 0.1649 & 0.1163 & 3.8000 \\
\hline deN041 & Asaba & Delta & 0.2417 & 0.2334 & 0.0341 & 14.1439 \\
\hline edN035 & Ehanlen-Ewu & Edo & 0.2029 & 0.1923 & 0.0524 & 9.0408 \\
\hline edN040 & Ugbokwi & Edo & 0.2239 & 0.2152 & 0.0389 & 12.3629 \\
\hline edN037 & Pax Benedicta Monastry & Edo & 0.2467 & 0.2375 & 0.0372 & 12.9513 \\
\hline enN055 & Ugwuomu & Enugu & 0.2188 & 0.206 & 0.0583 & 8.0747 \\
\hline enN053 & Orba1 & Enugu & 0.2161 & 0.2017 & 0.067 & 6.9667 \\
\hline goN068 & Nafada & Gombe & 0.2291 & 0.2184 & 0.0464 & 10.271 \\
\hline imN064 & Ahiazu Mbaise & Imo & 0.2316 & 0.2194 & 0.0527 & 8.9872 \\
\hline kaN033 & Tudun Wada & Kaduna & 0.2442 & 0.2336 & 0.0435 & 10.9819 \\
\hline knN078 & Kofar kudu & Kano & 0.2291 & 0.2174 & 0.0509 & 9.314 \\
\hline knN077 & Army Barracks & Kano & 0.2291 & 0.2152 & 0.0606 & 7.7465 \\
\hline kwN016 & Igosun & Kwara & 0.2367 & 0.2222 & 0.0612 & 7.6764 \\
\hline kwN015 & Sobi & Kwara & 0.2265 & 0.2154 & 0.0492 & 9.6609 \\
\hline niN018 & Bida & Niger & 0.2265 & 0.2164 & 0.0447 & 10.6764 \\
\hline ogN025 & Abeokuta & Ogun & 0.2392 & 0.2286 & 0.0445 & 10.7472 \\
\hline ogN028 & Covenant Univ & Ogun & 0.2316 & 0.2234 & 0.0356 & 13.5332 \\
\hline ogN076 & Kila & Ogun & 0.2188 & 0.2081 & 0.0486 & 9.7857 \\
\hline ogN026 & Olodo & Ogun & 0.2188 & 0.2091 & 0.0441 & 10.84 \\
\hline onN070 & Owena road & Ondo & 0.2213 & 0.2102 & 0.0504 & 9.4294 \\
\hline onN074 & Ondo - Ore road & Ondo & 0.2291 & 0.2194 & 0.0421 & 11.375 \\
\hline onN072 & OSUSTECH & Ondo & 0.2109 & 0.2017 & 0.0435 & 11 \\
\hline osN019 & Ipetumodu & Osun & 0.2291 & 0.2194 & 0.0421 & 11.375 \\
\hline osN020 & OAU & Osun & 0.2417 & 0.226 & 0.0649 & 7.2076 \\
\hline osN024 & Owode & Osun & 0.2213 & 0.2091 & 0.0551 & 8.5664 \\
\hline oyN003 & Aroje & Oyo & 0.2442 & 0.2336 & 0.0435 & 10.9819 \\
\hline oyN001 & Oke-oro Saki & Oyo & 0.2265 & 0.2132 & 0.0588 & 8.0050 \\
\hline oyN005 & Aba Oremeta Irawo & Oyo & 0.2188 & 0.2071 & 0.0534 & 8.8719 \\
\hline oyN004 & Sango, Ago Are & Oyo & 0.2291 & 0.2184 & 0.0464 & 10.2710 \\
\hline oyN009 & Alariwo Village & Oyo & 0.2316 & 0.2215 & 0.0437 & 10.9286 \\
\hline oyN010 & Okaka & Oyo & 0.2109 & 0.2026 & 0.0391 & 12.2768 \\
\hline plN030 & UniJos & Plateau & 0.2316 & 0.2194 & 0.0527 & 8.9872 \\
\hline soN066 & Along Sokoto road & Sokoto & 0.2367 & 0.2266 & 0.0428 & 11.1785 \\
\hline taN085 & Wukari (Fed. Univ) & Taraba & 0.2342 & 0.2235 & 0.0454 & 10.5102 \\
\hline yoN031 & Bukarti / Karasuwa & Yobe & 0.2342 & 0.2235 & 0.0454 & 10.5102 \\
\hline Ov mean & & & 0.2277 & 0.2166 & 0.0490 & 9.7066 \\
\hline St. Dev & & & 0.0001 & 0.0002 & & \\
\hline
\end{tabular}

Ov means- Overall mean, Total gene diversity, Ht; gene diversity within a population, Hs; coefficient of gene differentiation, Gst; and the estimate of gene flow, $\mathrm{Nm}$. 


\section{Cluster Analysis of 40 Accessions of Moringa oleifera using AFLP Data}

Cluster Analysis (CA) recorded a similarity coefficient scale of range 0.87 to 0.96 for the accessions. The 40 accessions were segregated into eleven different cluster groups as shown in Figure 3.

Cluster Membership

Cluster I: 2 accessions (AbNo57, AnNo46)

Cluster II: 24 accessions (60 \% of the total samples analyzed) (BeNo81 and EnNo53, EdNo35, EdNo55, OgNo76, KnNo77, KwNo16, OyNo01, OyNo05, OnNo70, OsNo20, OnNo72, OsNo24, KwNo15, OnNo74, OgNo26, NiNo18, OyNo09, OyNo10, GoNo68, KnNo78, ImNo64, KaNo33 and OgNo28).

Cluster III: 3 accessions (AnNo51, YoNo31, and OyNo04)

Cluster IV: 2 accessions (EdNo40, OgNo25)

Cluster V: 3 accessions (PINo30, SoNo66, and TaNo35)

Cluster VI: 1 accession (OsNo19)

Cluster VII: 1 accession (OyNo03)

Cluster VIII: 1 accession (EdNo37)

Cluster IX: 1 accession (AbNo59)

Cluster X: 1 accession (AnNo49)

Cluster XI: 1 accession (DeNo41). 


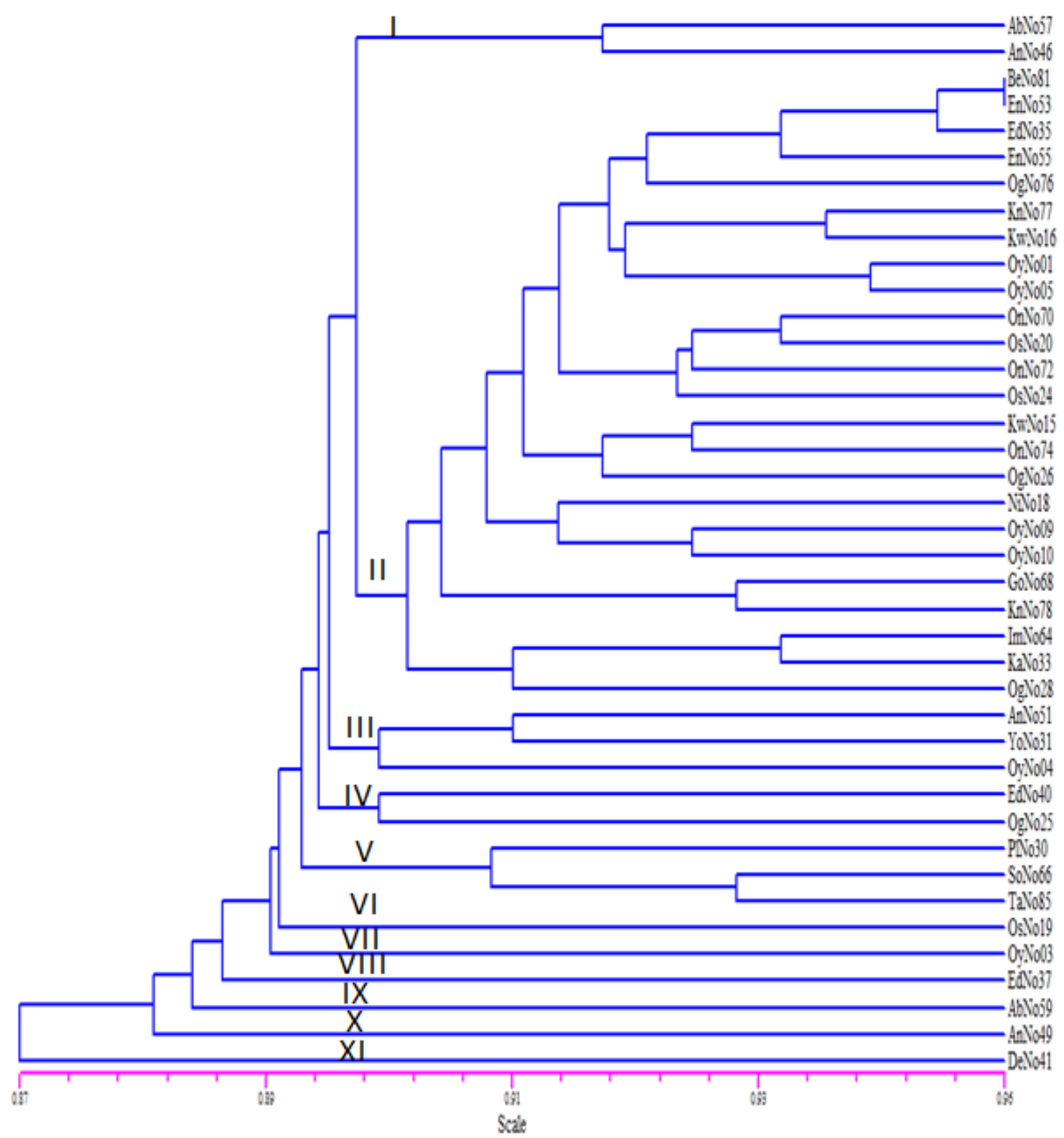

Figure 3: Dendrogram derived from 40 accessions of Moringa oleifera using amplified fragment length polymorphism markers 
Principal Component Analysis of 40 Accessions of Moringa oleifera using AFLP Data

The PCA generated a scattered plot which clustered the 40 accessions of $M$. oleifera into six major cluster groups (Fig. 4). Scattered clustered group I comprised of 6 accessions, cluster group II contained 9 accessions, group III has 4 accessions, cluster group IV contained 6 accessions, cluster group V consisted of 2 accessions while cluster group VI has a total of 13 accessions representing 32.5\% which cut across the southern and northern collections of M. oleifera in Nigeria (Fig 4).

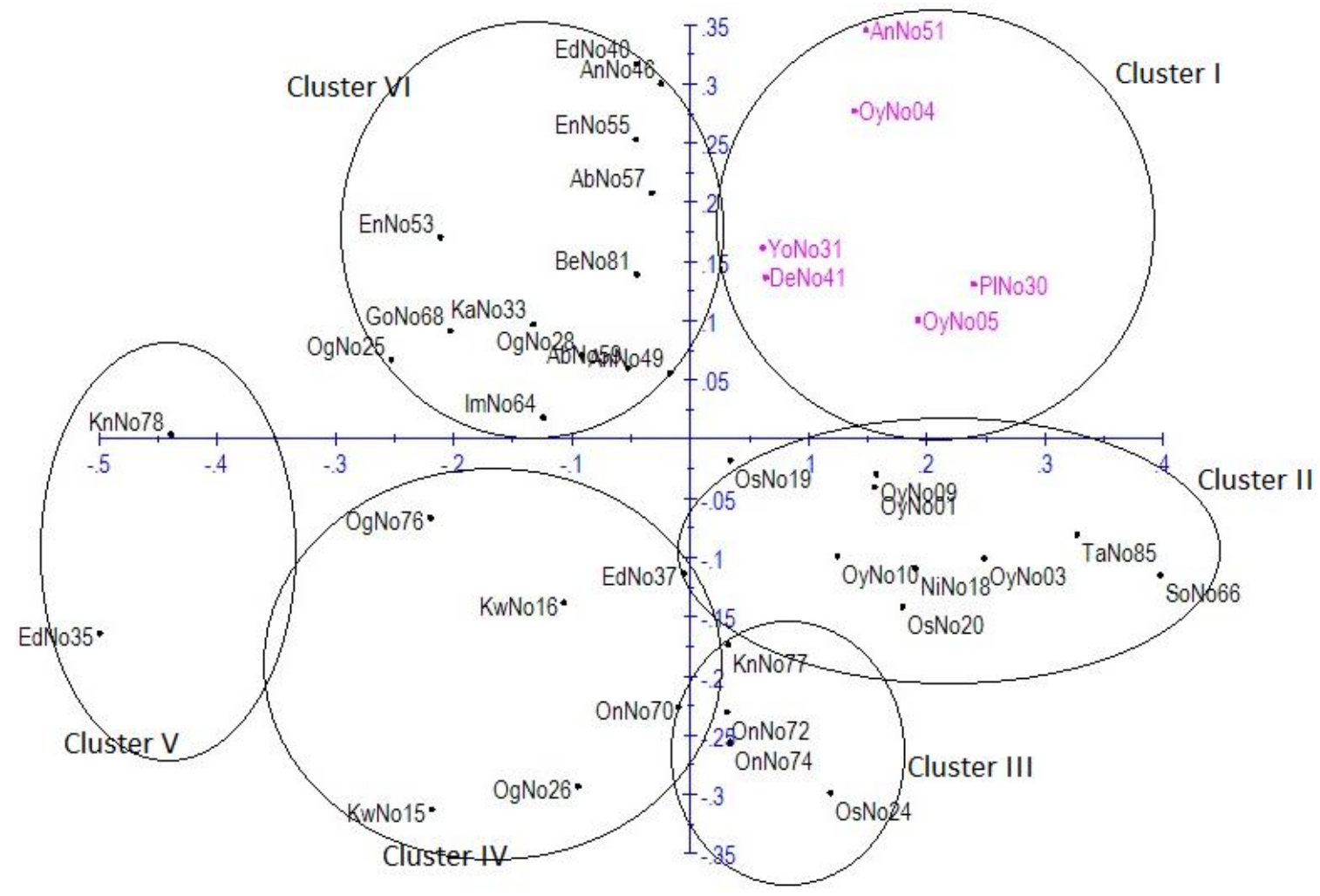

Figure 4: Principal component analysis of 40 accessions of Moringa oleifera using amplified fragment length polymorphism marker. 


\section{Discussion}

Tree species and their management systems are crucial to the sustainable provision of multiple products to meet human needs. Moringa oleifera is a small tree that can be cultivated as leafy vegetables as well as orchard trees [3]. In this present study, agronomic/silviculture management practices were considered to ensure a continuous supply of its various parts for food and nutritional security toward sustainable utilization of the species. Genetic diversity, population structure, and spread patterns were also evaluated targeted at breeding and management/conservation to achieve higher yield in leaf and seed production of Moringa oleifera in Nigeria.

\section{Agronomic/Silviculture Practices of Moringa oleifera from three locations}

The agronomic/silviculture practices adopted in this study contributed significantly to the leaf quantity production of Moringa oleifera accessions selected from the three locations in Nigeria. Reports have indicated that $M$. oleifera do not require high soil nutrients but adequate field maintenance and continuous soil management which could significantly increase leaf quantity production $[34,35]$. The physico-chemical properties of the soil were moderately acidic but richer in organic carbon, matter, nitrogen and other important minerals which enhanced the increased seedling growth of M. oleifera across the accessions from the locations. Thus, sandy soils that are rich in nutrients can be considered good for commercial cultivation of Moringa oleifera in Nigeria. All transplanted potted seedlings survived and maintained a continuous growth at the adopted spacing for the first 4 months of establishment indicating the richness of the soil. In addition, routine weeding of the most prominent weed (Pennisetum purpurium) observed on the field prevented loss of nutrients from the soil and enhanced healthy seedling growth. At different decapitulation levels of $20 \mathrm{~cm}, 40 \mathrm{~cm}$ and $60 \mathrm{~cm}$, respectively, steady increment of leafy production was observed while decapitation at $40 \mathrm{~cm}$ was found to be consistent and sustainable with high leaf quantity production across the location for the last two months of leaf harvesting. Decapitation of plant parts have been noted to enhance the induction of higher leaf production [36]. The findings of this study is also in agreement with the reports of Amadi [37] which revealed that height of decapitation significantly affected coppice potential of Plukenetia conophora seedlings. A frequent branch cutting of matured Moringa oleifera trees to stimulate higher leaf quantity production is highly effective [34]. Field preparation, soil properties, regeneration/ beating-up, pruning, stand development and harvesting are suitable procedures required for agronomic/silviculture practices of Moringa oleifera which have been implicated to influence new and higher leaf flush/yield, genetic diversity and for sustainable cultivation of tree species [38,39]. The combined silviculture practices and harvesting at different time intervals are suspected to have contributed to the continuous leaf production in this study. These practices need to be improved upon across Nigeria using more locations to meet the increasing demand for Moringa oleifera parts and its products for food and nutritional security as well as for good health.

\section{Genetic values of the AFLP primer pairs used in this study}

Several studies have shown that AFLP was more effective in identifying polymorphism to decipher genetic relationships among variable genotypes than either RAPD or RFLP [21,22]. In the present study, the AFLP analysis revealed a high genetic intra-specific diversity with over $95 \%$ of polymorphism recorded. The unevenness of specific band intensity, amplified product size distribution and overall banding pattern across the accessions/populations of M. oleifera contributed significantly to the variations observed. The size of AFLP fragments recorded across the 40 accessions was comparable to the sizes reported in recent studies carried out by $\mathrm{Wu}$ et al [40] but higher than that of Muluvi et al [13,15] carried out on populations of M. oleifera from Indian, Kenya, and Malawi. The two primer pairs (E-ACA/M-CAG and E-ACC/M-CAC) generated higher polymorphic loci, a very high PIC with a mean value of 0.974 and higher genetic diversity values than previous studies on tree species[41,42]. Thus, the primer pairs are highly discriminatory to effectively decipher the genetic relationship among the population of Moringa oleifera studied. The gene flow estimates were also comparatively high across the 20 populations of 40 accessions of M. oleifera which consequently 
influenced the level of genetic similarities as well as genetic divergence among and within the populations. The diversity values in individual populations ranged from 1.2295 (BeNo81 from Otukpo, Benue state) to 1.3274 (Pax Benedicta Monastery, Edo state) with a mean value of 1.2952 across the 20 populations with increased gene flow. The comparatively higher degree of polymorphism and heterogeneity as depicted in genetic diversity parameters is an indication of continuous domestication, cultivation and adaptation of $M$. oleifera ecotypes across the different regions of Nigeria $[8,25]$.

\section{Genetic diversity and population structure of Moringa oleifera in Nigeria}

The genetic diversity evaluation of the M. oleifera populations studied showed an increased diversity among the accessions collected from the southern parts of Nigeria compared to those from northern parts of Nigeria. For instance, the genetic diversity values were higher among the accessions from Edo state $(\mathrm{edNo} 35=1.2546$, edNo40 $=1.2886$, edNo37 $=1.3274)$, Abia state $(\mathrm{abNo} 57=1.3144$, $\mathrm{abNo} 57=1.3101$ ) compared to accessions from Benue state (beNo81 $=1.2295$ with lowest genetic diversity values) and Kano state ( $\mathrm{knNo} 77=1.2971$ and $\mathrm{knNo} 78=1.2971$, respectively). This pattern of genetic diversity has been reported among M. oleifera populations using SSR markers [8] even though the accessions of the populations were raised in the same environment of similar climatic and soil conditions. The low genetic divergence among the populations $(5 \%)$ and higher genetic differentiation within the populations ( $95 \%$ ) recorded in this study have been reported from previous studies which also identified a higher degree of genetic dissimilarities within-population compared to lower genetic diversity among the populations $[8,43]$. This trend of result can be attributed to the reproductive biology and pollination mechanisms of the species as an outcrossing and autogamous tree species with a higher rate of gene flow via pollen grains and exchange of propagules with nearby populations.

Dendrogram reconstruction and principal component analysis of Moringa oleifera accessions studied

The dendrogram and PCA analyses grouped some of the accessions along collection lines and eco-geographic distribution. From the CA, cluster group II was the most diverse group consisting of $60 \%$ of the accessions of M. oleifera landraces collected from diverse ecological areas. However, the grouping of two accessions BeNo81 from Benue state and EnNo53 from Enugu state together as an entity may likely reflect the genetic similarity in allele frequency and origin, even though the two landraces have been reported to be morphologically dissimilar $[3,8]$. Cluster groups III and IV did not show any alignment with their geographical origin rather than higher similarity in genetic diversity values. In contrast, six cluster groups (VI, VII, VIII, IX, X, and XI) were distinct and a clear departure from other groups which indicated higher genetic diversity. Therefore, the selection of parental lines from any of these groups will be of higher genetic gain for heterosis breeding with members of cluster group II for higher leaf quantity production. This will possibly enhance heterozygosity and strengthen genetic diversity in the M. oleifera gene pool.

The PCA scatter plot clustered the 40 accessions into six groups based on correlation with genetic diversity values and geographical location of a number of the accessions having connection with the accessions from the endemic areas of northern Nigeria. For instance, cluster groups I and II of PCA are mainly collections from southern Nigeria with a strong link to one or more collections from northern Nigeria states of Yobe and Plateau (YoNo31 and PINo30), and Taraba and Sokoto states (TaNo85 and SoNo66), respectively. Clustering accessions from northern Nigeria (YoNo31 and PINo30 in cluster group I; TaNo85 and SoNo66 in cluster group II; KnNo77 in cluster group III, $\mathrm{KwNo15}$ and $\mathrm{KwNo16}$ in cluster group IV, $\mathrm{KnNo} 78$ in cluster group V and BeNo81 in cluster group VI) are remarkable as endemic regions/areas and represent the center of spread of accessions (EnNo53, EnNo55, and AnNo51) to the southeast of Nigeria. This may reflect the commonality in the sources of spread of the accessions and hence the center of spread to be northern Nigeria. However, the cluster membership reveals that the accessions spread southward across the northcentral to the east and the western part of the country. This spread pattern may be linked to the movement pattern of the Hausa traders, who were reported as the major dispersal agents of the species across the different 
eco-geographical zones of Nigeria until recently [25]. The closeness of the accessions AbNo57 from Okpanku (Abia state) and AnNo46 from Unizik (Anambra state) (Figures 3 and 4) may be attributed to a common source as Hausa traders move around the states of the collection sites. The morphological differences reported earlier can be attributed to the selection pressure created by the environmental (altitudinal) differences between the collection sites [3,12]. The primary center of spread of these accessions can be traced to the northcentral region of Nigeria comprising of Benue, Gombe and Kaduna states as depicted in scattered cluster group VI of PCA (Figure 4).

Accessions segregated in dendrogram clusters I, II, III, IV, V, and VI shared similarity indices that reflected their genetic closeness, although most accessions did not align along collection lines. Expectedly, the spread of the accessions was southward from the north. The cluster II accession members can be linked to Kaduna, a central city and former capital of northern Nigeria as the primary spread point. If the primary materials originated from the Middle East or India, Kaduna would fit well as a point of primary naturalization and a center from where the species is distributed across other parts of Nigeria through the trade routes. The accessions spread routes may have commenced separately or simultaneously through the northcentral region (Kwara state with accessions KwNo15 and KwNo16, Plateau state with PINo30 and Benue state route, with accession BeN081) or through the southwest region (OgN076, OsN020, among others) as revealed by the clustering pattern (Fig. 3). The accessions grouped in cluster group $\mathrm{V}$ of dendrogram are interestingly restricted to northern Nigeria while cluster group II of PCA is diverse though shared genetic relationship with the former. Members of these clusters shared a commonality that reflected eco-geographical confinement to the north and southwest, Nigeria. However, the accessions in cluster II of PCA, like other clusters share a close affinity with an accession from the northern Nigeria (NiN018). The collection site for this accession from Bida (Niger state) may have housed the taxon population that spread southward and constitute a center of spread for this group of accessions. The spread of these accessions from the north (Bida) may not be connected with the Hausa traders' movement as earlier suggested for others, but may be linked to the Yoruba trading tribesmen - the Ogbomosho traders, known to spread across the West African regions and established a sizeable settlement in Niger state (Bida), Nigeria. Cluster III and V grouped only four and two accessions, respectively with direct link with some of the southernmost accessions (OnNo72, OnNo74, OsNo24) and (EdNo35) and two northern accessions (KnNo77 and KnNo78). These accessions probably have the most authentic recorded age of all the accessions [25] and were said to be introduced by a returning retired administrator from northern Nigeria and may have their origin in Kano, another major commercial city in northern Nigeria. However, the lack of spread of the species in southern Nigeria may point to a grossly undercultivated and under-exploited status of the M. oleifera genetic resources in Nigeria.

\section{Center of endemism and spread pattern of Moringa oleifera in Nigeria}

Ethnobotanical studies of M. oleifera [25], have shown that the taxon has long been utilized in northern Nigeria before its introduction to the southern part of Nigeria. The dendrogram and PCA revealed the spread pattern of $M$. oleifera in Nigeria as southward from the north, with the northern Nigeria constituting the primary area of naturalization and endemism of M. oleifera in Nigeria. The present molecular study highlights the possible centers from whence the southward spread of $M$. oleifera in Nigeria commenced. These centers include; Sokoto/Yobe, with accessions that are of disparate spread throughout the southern Nigeria; Kaduna, with accessions accounting for most of the accessions recorded in the southeast; Bida, with accessions restricted in spread to the South West and Kano, with the least exploited accessions and a restricted spread line in the South-South and southwest of Nigeria. These centers and accessions identified from the centers present good candidates as model accessions for research and development of improved lines for M. oleifera cultivation in Nigeria.

\section{Conclusions}


Agronomic practices are critical strategies to be considered in sustainable agriculture to ensure food production and nutritional security. Though the four agronomic practices adopted in this study remain localized, their effects on leaf quantity production of $M$. oleifera were impressive. Therefore efforts should be intensified to modernize and strengthen such practices for commercial purposes. Likewise, accessions from the endemic areas of northern Nigeria and fast-growing accessions from southern Nigeria can be utilized for higher leaf production to meet the high demand for Moringa leaves as leafy vegetable. M. oleifera in Nigeria exhibits high polymorphism and genetic variation necessary for survival, utilization, conservation, and genetic improvement. This variation is reinforced by the number of possible routes of introduction of the species into Nigeria, the established centers of spread, the pattern of spread and adaptation of the taxon across the different ecogeographical zones in the country. The AFLP markers utilized in this study highlighted the genetic richness available in $M$. oleifera, which can be articulated with agro-morphological characters for breeding purposes.

Author Contributions: Conceptualization, Jacob Popoola; methodology, J.P.; software, D.I.; validation, J.P., C.O. and O.J.; formal analysis, D.I.; investigation, V.I; resources, J.P.; writing-original draft preparation, J.P.; writing - review and editing, J.P. and A.A; supervision, C.O.

Funding: This research received no external funding.

Acknowledgments: The authors acknowledge the publication support given to this work by the Covenant University Center for Research Innovation and Discovery (CUCRID). We also thank anonymous reviewers for their contribution to this manuscript.

Conflicts of Interest: The authors declare no conflict of interest.

\section{References}

1. Padulosi, S.; Eyzaquirre, P.; Hodgkin, T. Challenges and strategies in promoting conservation and use of neglected and underutilized crop species. Perspectives on new crops and new uses 1999, 140-145.

2. Popoola, J.; Ojuederie, O.; Omonhinmin, C.; Adegbite, A. Neglected and Underutilized Legume Crops: Improvement and Future Prospects. In Recent Advances in Grain Crops Research, IntechOpen: 2019.

3. Popoola, J.O.; Bello, O.A.; Obembe, O.O. Phenotypic intraspecific variability among some accessions of drumstick (Moringa oleifera Lam.). Canadian Journal of Pure and Applied Sciences 2016, 10, 3681-3693.

4. Anwar, F.; Latif, S.; Ashraf, M.; Gilani, A.H. Moringa oleifera: a food plant with multiple medicinal uses. Phytotherapy research : PTR 2007, 21, 17-25, doi:10.1002/ptr.2023.

5. Aa, A.B.; Om, J.; Ts, E.; Ga, A. Preliminary phytochemical screening, antioxidant and antihyperglycaemic activity of Moringa oleifera leaf extracts. Pakistan journal of pharmaceutical sciences 2017, 30, 2217-2222.

6. Abdull Razis, A.F.; Ibrahim, M.D.; Kntayya, S.B. Health benefits of Moringa oleifera. Asian Pacific Journal of Cancer Prevention : APJCP 2014, 15, 8571-8576, doi:10.7314/apjcp.2014.15.20.8571.

7. Barrado-Moreno, M.M.; Beltran-Heredia, J.; Martin-Gallardo, J. Microalgae removal with Moringa oleifera. Toxicon : Official Journal of the International Society on Toxinology 2016, 110, 68-73, doi:10.1016/j.toxicon.2015.12.001.

8. Popoola, J.O.; Bello, O.A.; Olugbuyiro, J.; Obembe, O.O. Simple sequence repeats (SSR) analysis of genetic intraspecific relationships of Moringa oleifera populations from Nigeria. Sci. Int. (Lahore) 2017, $29,645-657$.

9. Igwe, D.O.; Afiukwa, C.A.; Ubi, B.E.; Ogbu, K.I.; Ojuederie, O.B.; Ude, G.N. Assessment of genetic diversity in Vigna unguiculata L.(Walp) accessions using inter-simple sequence repeat (ISSR) and start codon targeted (SCoT) polymorphic markers. BMC genetics 2017, 18, 98. 
10. Wang, C.; Hu, S.; Gardner, C.; Lübberstedt, T. Emerging avenues for utilization of exotic germplasm. Trends in Plant Science 2017, 22, 624-637.

11. Ojuederie, O.B.; Balogun, M.O.; Fawole, I.; Igwe, D.O.; Olowolafe, M.O. Assessment of the genetic diversity of African yam bean (Sphenostylis stenocarpa Hochst ex. A Rich. Harms) accessions using amplified fragment length polymorphism (AFLP) markers. African Journal of Biotechnology 2014, 13.

12. Popoola, J.O.; Oluyisola, B.O.; Obembe, O.O. Genetic diversity in Moringa oleifera from Nigeria using fruit morpho-metric characters and Random Amplified Polymorphic DNA (RAPD) markers. Covenant Journal of Physical and Life Sciences (CJPL). 2014, 43-60.

13. Muluvi, G.M.S., J.I. Odee, D. Powell, W. Estimates of outcrossing rates in Moringa oleifera using Amplified fragment length polymorphism (AFLP). African Journal of Biotechnology: 2004; Vol. 3, pp 146151.

14. Abubakar, B.; Wusirika, R.; MuA'zu, S.; Khan, A.; Adamu, A. Detection of genetic variability using random amplified polymorphic DNA markers in some accessions of Moringa oleifera Lam. from northern Nigeria. Int. J. Bot 2011, 7, 237-242.

15. Muluvi, G.M.; Sprent, J.I.; Soranzo, N.; Provan, J.; Odee, D.; Folkard, G.; McNicol, J.W.; Powell, W. Amplified fragment length polymorphism (AFLP) analysis of genetic variation in Moringa oleifera Lam. Molecular ecology 1999, 8, 463-470, doi:10.1046/j.1365-294x.1999.00589.x.

16. Zhou, C.P.; Qi, Y.P.; You, X.; Yang, L.T.; Guo, P.; Ye, X.; Zhou, X.X.; Ke, F.J.; Chen, L.S. Leaf cDNAAFLP analysis of two citrus species differing in manganese tolerance in response to long-term manganese-toxicity. BMC Genomics 2013, 14, 621, doi:10.1186/1471-2164-14-621.

17. Ammar, M.H.; Alghamdi, S.S.; Migdadi, H.M.; Khan, M.A.; El-Harty, E.H.; Al-Faifi, S.A. Assessment of genetic diversity among faba bean genotypes using agro-morphological and molecular markers. Saudi J Biol Sci 2015, 22, 340-350, doi:10.1016/j.sjbs.2015.02.005.

18. Agarwal, M.; Shrivastava, N.; Padh, H. Advances in molecular marker techniques and their applications in plant sciences. Plant Cell Rep 2008, 27, 617-631, doi:10.1007/s00299-008-0507-z.

19. Halász, J.; Kodad, O.; Galiba, G.M.; Skola, I.; Ercisli, S.; Ledbetter, C.A.; Hegedűs, A. Genetic variability is preserved among strongly differentiated and geographically diverse almond germplasm: an assessment by simple sequence repeat markers. Tree Genetics \& Genomes 2019, 15, 12.

20. Mueller, U.G.; Wolfenbarger, L.L. AFLP genotyping and fingerprinting. Trends in Ecology E Evolution 1999, 14, 389-394.

21. Mignouna, H.; Abang, M.; Fagbemi, S. A comparative assessment of molecular markers assays (AFLP, RAPD and ISSR) for white yam (Dioscorea rotundata) germplasm characterization. Annals of Applied Biology 2003; pp 269 -276.

22. Albrecht, E.; Zhang, D.; Mays, A.D.; Saftner, R.A.; Stommel, J.R. Genetic diversity in Capsicum baccatum is significantly influenced by its ecogeographical distribution. BMC genetics 2012, 13, 68.

23. Rufai, S.; Hanafi, M.M.; Rafii, M.Y.; Ahmad, S.; Arolu, I.W.; Ferdous, J. Genetic dissection of new genotypes of drumstick tree (Moringa oleifera Lam.) using random amplified polymorphic DNA marker. BioMed research international 2013, 2013, 604598, doi:10.1155/2013/604598.

24. Houba, V.; Temminghoff, E.; Gaikhorst, G.; Van Vark, W. Soil analysis procedures using $0.01 \mathrm{M}$ calcium chloride as extraction reagent. Communications in soil science and plant analysis 2000, 31, 1299-1396.

25. Popoola, J.O.; Obembe, O.O. Local knowledge, use pattern and geographical distribution of Moringa oleifera Lam. (Moringaceae) in Nigeria. Journal of Ethnopharmacology 2013, 150, 682-691, doi:10.1016/j.jep.2013.09.043. 
26. Dellaporta, S.L.; Wood, J.; Hicks, J.B. A plant DNA minipreparation: version II. Plant Molecular Biology Reporter 1983, 1, 19-21.

27. Hepperle, D. Align, Multisequence Alignment Editor ver. 05/2008 SequentiX-Digital DNA Processing, Klein Raden, Germany. 2008.

28. Liu, K.; Muse, S. PowerMaker: An integrated analysis environment for genetic maker analysis. North Carolina State University. Bioinformatics Research Center. doi 2005, 10.

29. Shannon, C.E.; Weaver, W. The Mathematical Theory of Communication; University of Illinois Press: 1998.

30. Popoola, J.O.; Egwari, L.O.; Adekunle, A.; Ogunlana, O.O.; Omonhinmin, C.A. Genetic Variability and Development of Cassava Based Products Using Morphometric and RAPD Markers. Asian Journal of Plant Sciences 2019, 18, 26-32.

31. Yeh, F.C.; Yang, R.; Boyle, T.B.; Ye, Z.; Mao, J.X. POPGENE version 1.32, the user-friendly shareware for population genetic analysis. Molecular Biology and Biotechnology Centre, University of Alberta, Canada 1999.

32. Rohlf, F. NTSYS-pc: Numerical Taxonomy System ver. 2.1. Setauket, NY: Exeter Publishing Ltd 2002.

33. Jaccard, P. Nouvelles recherches sur la distribution florale. Bull. Soc. Vaud. Sci. Nat. 1908, 44, 223-270.

34. Foidl, N.; Bennett, R.; Ellis, W.; Timpo, G.; Amaglo, N. Effect of spacing and harvest frequency on the growth and leaf yield of moringa (Moringa oleifera Lam), a leafy vegetable crop. 2007.

35. Foidl, N.; Makkar, H.; Becker, K. The potential of Moringa oleifera for agricultural and industrial uses. The miracle tree: The multiple attributes of Moringa 2001, 45-76.

36. Adegun, M.K.; Ayodele, O.J. Growth and yield of Moringa oleifera as influenced by spacing and organic manures in South-Western Nigeria. International Journal of Agronomy and Agricultural Research 2015, 6, 30-37

37. AMADI, J.O. Silvicultural requirements for conservation of Plukenetia conophora (MULL ARG) IN SOUTHWESTERN NIGERIA. 2014.

38. Carnus, J.-M.; Parrotta, J.; Brockerhoff, E.; Arbez, M.; Jactel, H.; Kremer, A.; Lamb, D.; O’Hara, K.; Walters, B. Planted forests and biodiversity. Journal of Forestry 2006, 104, 65-77.

39. Palada, M.; Chang, L.-C. Suggested cultural practices for Moringa. International Cooperators' Guide AVRDC. AVRDC pub 2003, 03-545.

40. Wu, W.-D.; Liu, W.-H.; Sun, M.; Zhou, J.-Q.; Liu, W.; Zhang, C.-L.; Zhang, X.-Q.; Peng, Y.; Huang, L.K.; Ma, X. Genetic diversity and structure of Elymus tangutorum accessions from western China as unraveled by AFLP markers. Hereditas 2019, 156, 8.

41. Ojuederie, O.B.; Igwe, D.O.; Okuofu, S.I.; Faloye, B. Assessment of genetic diversity in some Moringa oleifera Lam. landraces from Western Nigeria using RAPD markers. African Journal of Plant Science and Biotechnology 2013, 7, 15-20.

42. Hagen, L.; Khadari, B.; Lambert, P.; Audergon, J.-M. Genetic diversity in apricot revealed by AFLP markers: species and cultivar comparisons. Theoretical and Applied Genetics 2002, 105, 298-305.

43. Amusa, O.; Adesoye, A.; Ogunkanmi, A.; Omoche, O.; Olowe, O.; Akinyosoye, S.; Omodele, T. Genetic diversity of Parkia biglobosa from different agroecological zones of Nigeria using RAPD Markers. International Journal of Biodiversity 2014, 2014. 